\title{
How "dirty" is the Dark Triad? Dark character profiles, swearing, and sociosexuality
}

\author{
Danilo Garcia ${ }^{\text {Corresp. 1,2,3 }}$ \\ ${ }^{1}$ Department of Behavioral Sciences and Learning, Linköping University, Linköping, Sweden \\ 2 Department of Psychology, University of Gothenburg, Gothenburg, Sweden \\ 3 Blekinge Center of Competence, Region Blekinge, Karlskrona, Sweden \\ Corresponding Author: Danilo Garcia \\ Email address: danilo.garcia@icloud.com
}

Malevolent character traits (i.e., the Dark Triad: Machiavellianism, narcissism, and psychopathy) are associated to emotional frigidity, antagonism, immoral strategic thinking, betrayal, exploitation, and sexual promiscuity. Despite the fact that character is a complex adaptive system, almost every study has solely investigated the linear association between malevolent character and attitudes towards both swearing and sociosexual orientation (i.e., behavior, attitude, and desire regarding promiscuous sexual behavior). In contrast, the aim in this set of studies was to evaluate these associations in relation to specific profiles of malevolent character (i.e., the Dark Cube). In two studies participants responded to the Dark Triad Dirty Dozen, the Taboo Words' Offensiveness and Usage Inventories (i.e., attitudes towards 30 swear words' level of offensiveness and usage) (Study 1: $N_{1}=1000$ ) and the Sociosexual Orientation Inventory Revised (Study 2: $N_{2}=309$ ). Participants were clustered according to all eight possible combinations based on their dark trait scores $(\mathrm{M} / \mathrm{m}=$ high/low Machiavellianism; $\mathrm{N} / \mathrm{n}=$ high/low narcissism; $\mathrm{P} / \mathrm{p}$ $=$ high/low psychopathy). The results of this nonlinear approach suggested that the frequent usage, not level of offensiveness, of swear words was associated to Machiavellianism and narcissism. In other words, individuals with high levels in these traits might swear and are verbally offensive often because they do not see swearing as offensive (cf. with the attitude-behavior-cognition-hypothesis of taboo words; Rosenberg, Sikström \& Garcia, 2017). Moreover, promiscuous sociosexual attitude and desire were related to each dark trait only when the other two were low. Additionally, promiscuous sociosexual behavior was not associated to these malevolent character traits. That is, individuals high in the dark traits are willing to and have the desire to engage in sexual relations without closeness, commitment, and other indicators of emotional bonding. However, they do not report high levels of previous sexual experience, relationships, and infidelity. Hence, they approve and desire for it, but they are not actually doing it. The 
present investigation presented a nonlinear approach to the study of the Dark Triad traits and their "dirty" behavior, in this case swearing and sociosexuality. The use of personcentered and non-linear methods, such as the Dark Character Cube, are helpful in the advancement of a coherent theory of a biopsychosocial model of dark character. 


\section{Submitted to PeerJ}

2 Please do not quote or cite without permission

3

4

5

6

7

8

9

10

11

12

13

14

15

16

17

18

19

20

21

22

23

\section{How "Dirty" is the Dark Triad?}

Dark Character Profiles, Swearing, and Sociosexuality

Danilo Garcia ${ }^{1,2,3 *}$
${ }^{1}$ Department of Behavioral Sciences and Learning, Linköping University, Linköping, Sweden ${ }^{2}$ Department of Psychology, University of Gothenburg, Gothenburg, Sweden ${ }^{3}$ Blekinge Center of Competence, Region Blekinge, Karlskrona, Sweden Email: danilo.garcia@icloud.com




\section{Abstract}

27 Malevolent character traits (i.e., the Dark Triad: Machiavellianism, narcissism, and psychopathy) 28 are associated to emotional frigidity, antagonism, immoral strategic thinking, betrayal, exploitation, and sexual promiscuity. Despite the fact that character is a complex adaptive system, almost every study has solely investigated the linear association between malevolent character and attitudes towards both swearing and sociosexual orientation (i.e., behavior, attitude, and desire regarding promiscuous sexual behavior). In contrast, the aim in this set of studies was to evaluate these associations in relation to specific profiles of malevolent character (i.e., the Dark Cube). In two studies participants responded to the Dark Triad Dirty Dozen, the Taboo Words' Offensiveness and Usage Inventories (i.e., attitudes towards 30 swear words' level of offensiveness and usage) (Study 1: $N_{l}=1000$ ) and the Sociosexual Orientation Inventory Revised (Study 2: $N_{2}=309$ ). Participants were clustered according to all eight possible combinations based on their dark trait scores $(\mathrm{M} / \mathrm{m}=$ high/low Machiavellianism; $\mathrm{N} / \mathrm{n}=$ high/low narcissism; $\mathrm{P} / \mathrm{p}=$ high/low psychopathy). The results of this nonlinear approach suggested that the frequent usage, not level of offensiveness, of swear words was associated to Machiavellianism and narcissism. In other words, individuals with high levels in these traits might swear and are verbally offensive often because they do not see swearing as offensive (cf. with the attitude-behavior-cognitionhypothesis of taboo words; Rosenberg, Sikström \& Garcia, 2017). Moreover, promiscuous sociosexual attitude and desire were related to each dark trait only when the other two were low. Additionally, promiscuous sociosexual behavior was not associated to these malevolent character traits. That is, individuals high in the dark traits are willing to and have the desire to engage in sexual relations without closeness, commitment, and other indicators of emotional bonding. However, they do not report high levels of previous sexual experience, relationships, and infidelity. Hence, they approve and desire for it, but they are not actually doing it. The present investigation presented a nonlinear approach to the study of the Dark Triad traits and their "dirty" behavior, in this case swearing and sociosexuality. The use of person-centered and non-linear methods, such as the Dark Character Cube, are helpful in the advancement of a coherent theory of a biopsychosocial model of dark character. 
55 Keywords: Character, Dark Cube, Dark Triad, Machiavellianism, Narcissism, Psychopathy,

56 Sociosexuality, Swearing, Unification vs. Uniqueness Debate

57

"I love French wine, like I love the French language. I have sampled every language, French is my favorite. Fantastic language. Especially to curse with: Nom de dieu de putain de bordel de merde de saloperie de connard d'enculé de ta mère.

It's like wiping your arse with silk. I love it."

"Choice is an illusion created between those with power and those without."

"Please, ma cherie. I have told you. We are all victims of causality. I drank too much wine, I must take a piss. Cause and effect."

The Merovingian in Matrix Reloaded

Dark personality traits are expressed as manipulativeness, a cynical worldview and lack morality (i.e., Machiavellianism), a sense of grandiosity and vulnerable self-esteem (i.e., narcissism), and also low conscientiousness, high impulsivity, and high levels of thrill-seeking behavior (i.e., psychopathy). Although each of these behaviors are associated with a specific dark character trait (Paulhus \& Williams, 2002; Furnham, Richards \& Paulhus, 2013, Hare,1985; Jones \& Paulhus, 2009; 2014), individuals high in any of the dark character traits tend to be uncooperative and unagreeable (Garcia, Adrianson, Archer \& Rosenberg, 2015; Garcia \& Rosenberg, 2016; Kajonious, Persson, Rosenberg \& Garcia, 2016). In other words, malevolent character seems to be

4 a form of immature character ${ }^{1}$ expressed as being unempathetic, lacking self-control, and having low "moral intuition". Individuals high in these dark traits often use violence (both verbal and

\footnotetext{
${ }^{1}$ See for example Cloninger, 2004, who defines a mature character as high levels in three character traits: selfdirectedness, cooperativeness, and self-transcendence (see also Garcia \& Rosenberg, 2016).
} 
76 physical) and also promiscuous and "dirty" behavior to manipulate or submit others in order to

77 gain power or fulfill own desires (i.e., an outlook of separation), hence, they lack a sense for

78 cooperation and altruism (i.e., an outlook of unity; Cloninger, 2004).

79 For instance, swear words, which main purpose is to express emotions, especially anger 80 and frustration (Jay, 2000; Jay \& Janschewitz, 2008), are more frequently used by individuals who 81 are higher in the dark character traits. More specifically, words that express anger and negative 82 emotion seem to be more frequently used by individuals high in Machiavellianism and 83 psychopathy, while words related to sex are more frequently used by individuals high in narcissism 84 (Sumner, Byers, Boochever \& Park, 2012). Importantly, a wide range of research suggest that swearing, in moderation, may increase pain tolerance (Stephens, Atkins \& Kingston, 2009) and even reduce stress (Byrne, 2018). Hence, it is important to understand the mechanism behind 87 swearing in relation to dark personality traits. In this context, according to the (A)attitude(B)behavior-(C)cognition-hypothesis of taboo words, the level of offensiveness of swear words predicts how often people swear (Rosenberg, Sikström \& Garcia, 2017). Thus, the way the individual perceives how offensive the word is and how often she/he uses the swear word are two separate features that might relate differently to high levels of the dark traits. If it is so, individuals who score high in the dark traits are expected to swear often and to not see the swearing words they use as offensive. with regard to a person's attitude towards sexual life. Individuals, specially males, who are high in the dark traits use an exploitative short-term mating strategy ${ }^{2}$, that is, an strategy with tactics to

97 avoid entangling commitments (Jonason, Li, Webster \& Schmitt, 2009; Jonason, Li \& Czarna,

\footnotetext{
2 According to evolutionary psychology, human mating strategies tend to range from short-term relationships to longterm relationships characterized by little and heavy commitment, respectively (Buss, 2019).
} 
98 2013; Jonason \& Buss, 2012; Gonzalez Moraga, Nima \& Garcia, 2017). In this context,

99 sociosexuality or differences in a person's willingness to engage in sexual relations without

100 closeness, commitment, and other indicators of emotional bonding, can be understood in three

101 different components: sociosexual behavior (i.e., individuals' previous sexual experience,

102 relationships, and infidelity), sociosexual attitude (i.e., aspects of behavior and desire influenced

103 by moral feelings, reflections and self-presentation based on values, habits and social effects), and

104 sociosexual desire (i.e., the notion of a dispositional motivation that refers to effort given to

105 temporary and long-term sexual relationships) (Penke \& Asendorf, 2008; Simpson \& Gangestad,

106 1992). Importantly, past findings on the main effects of high levels of socosexuality on people's

107 health range from negative to positive to even nonsignificant (Vrangalova \& Ong, 2014).

108 In sum, the relationship between "dirty" behavior and malevolent character is not 109 consistent. One probable part of this shortcoming might be the current understanding of traits as 110 the basic unit of personality (Cloninger \& Zwir, 2018; Cloninger, Cloninger, Zwir \& Keltikangas-

111 Järvinen, 2020). Most of the current studies on dark traits, if not all, conduct some type of

112 association analyses between the malevolent dark traits and different outcomes. Molecular studies,

113 however, indicate that the basic unit of personality is actually profiles, not traits (see Zwir et al.,

114 2018ab; 2019ab; Cloninger \& Cloninger, 2019). Therefore, the purpose of the present study is to

115 test a relatively new approach, the Dark Cube, to study the relationship between the dark traits and 116 peoples' swearing and sociosexuality. The question is if this approach adds any new information

117 to the common linear correlation approach.

\section{The Dark Cube}

119 The Dark Cube (Garcia \& Rosenberg, 2016; Garcia, 2018; Garcia \& González Moraga, 2017;

120 Garcia, Rosenberg, González Moraga \& Rapp Ricciardi, 2018) is based on the presupposition that 
121 the Dark Triad is composed of overlapping yet distinctive constructs that can be measured

122 separately (Paulhus \& Williams, 2002) but that may vary within the individual. Hence, the Dark

123 Cube consists of all eight possible combinations of high/low scores in the three dark traits (Figure

124 1). This is one way of addressing personality traits as a whole system unit or a dynamic complex

125 adaptive system (cf. Cloninger, 2004). This approach allows for the nonlinear investigation of, in

126 this case, malevolent character profiles (see also Bergman \& Wångby, 2014; Bergman \&

127 Magnusson, 1997; Cloninger, Svrakic \& Svrakic, 1997). For instance, despite the fact that some

128 studies using the Big Five traits (Costa, McCrae \& Dye, 1991; John \& Srivastava, 1999; González

129 Moraga, 2015) have found associations between, for example, neuroticism and some of the dark

130 traits, these associations are not consistent in the literature (Vernon, Villani, Vickers \& Harris,

131 2008). Studies using the Dark Cube on the other hand, show that Big Five traits and the malevolent

132 characters traits are associated only under certain conditions, thus, probably explaining the

133 inconsistencies in the literature (Garcia, 2018). For example, while high levels of narcissism are

134 associated to high levels of extraversion and high levels of psychopathy are associated to high

135 levels of low agreeableness per se; high Machiavellianism was associated to high neuroticism only

136 when both narcissism and psychopathy were low, high narcissism and high conscientiousness were

137 associated only when both Machiavellianism and psychopathy were also high, and high

138 psychopathy and high neuroticism were associated only when Machiavellianism was low and 139 narcissism was high (Garcia \& González Moraga, 2017). In other words, the Dark Cube analyses

140 showed how the complex interactions between dark traits within the individual, an interaction that

141 is often ignored in a majority of studies, may explain inconsistencies, such as, why high levels of

142 psychopathy are in some studies associated to high levels of neuroticism and not associated at all

143 in others (Garcia, Adrianson, Archer \& Rosenberg, 2015). More specifically, the Dark Cube 
144 analyses suggest that individuals high in psychopathy have a proneness to worry, rumination,

145 hostility, sadness, hopelessness, impulsiveness, and sensitivity in social situations (i.e., high

146 neuroticism) if they are also low in manipulative tendencies and highly narcissistic at the same

147 time (Garcia \& González Moraga, 2017). Hence, the Dark Cube, with its eight dark malevolent

148 profiles, is a tool that might help to clarify some of the mixed and inconsistent associations in the

149 Dark Triad literature (Garcia, 2018).

150

Figure 1 should be about here

\section{The present set of studies}

152 The aim in this set of studies was to evaluate the interactions among specific combinations of 153 malevolent character traits in relation to swearing (Study 1) and sociosexuality (Study 2). The

154 question is if the Dark Cube approach adds more information to the common linear analyses used 155 in most studies. More specifically, this set of studies comprises the investigation of the relationship 156 between malevolent character traits and "dirty" behavior (i.e., swearing and sociosexual 157 orientation) using non-linear methods (i.e., comparisons between individuals who differed in one 158 malevolent character trait but were alike in the other). This approach considers the complexity of 159 processes within the person (cf. Cloninger \& Zohar, 2011). The multidimensionality of swearing 160 (how offensive a word is vs. how often the word is used) and sociosexuality (behavior, attitude, 161 and desire) was expected to be a function of a complex interaction: the same malevolent character 162 trait could lead to different "dirty" behavior (i.e., multi-finality), but also that different malevolent 163 character traits could lead to the same "dirty" behavior (i.e., equifinality) (cf. Cicchetti \& Rogosch, 164 1996).

165 Ethics Statement 
166 Since the study did not involve a physical intervention and no information on individual health

167 issues was involved in the study, there was no need to involve the ethical board, according to

168 Swedish law at the time the data was collected (2014-2015). The World Medical Association

169 Declaration of Helsinki (1964) was followed. Participants, workers from the crowdsourcing

170 platform Amazon's Mechanical Turk, provided their consent by simply accepting the task (or HIT

171 as it's called in Amazon Mechanical Turk) and then starting to answer the survey. This acceptance

172 is recorded electronically together with the participants' answers.

173

\section{Study 1: Swearing}

\section{Method}

\section{Participants and Procedure}

176 Participants in Study 1 were recruited from Amazon's Mechanical Turk and got paid \$ 0.50 dollars

177 for taking the survey (data from Rosenberg, Sikström \& Garcia, 2017). Participants answered to

178 measures of the Dark Triad and both perception and usage of swear words, and also to 179 demographic questions (e.g., gender, age) and two control questions (e.g. "In this question please 180 answer Neither agree or disagree"). A total of 50 participants were removed (i.e., $4.76 \%$ ) from the 181 final sample due to erroneous answer to one or both control questions. This final sample consisted 182 of 1000 US-residents, 333 women and 667 men $\left(N_{l}=1000, M_{\text {age }}=31.50 \pm 10.27\right)$.

\section{Measures}

184 Dark Traits. The Dark Triad Dirty Dozen (Jonason \& Webster, 2010) consists of 12 statements (1 185 = strongly disagree, 7 = strongly agree), four statements for each dark trait: Machiavellianism ("I 186 tend to manipulate others to get my way"; Cronbach's $\alpha=.78$ ), narcissism ("I tend to want others 187 to admire me"; Cronbach's $\alpha=.77$ ), and psychopathy ("I tend to be unconcerned with the morality 188 of my actions"; (Cronbach's $\alpha=.76)$. 
190 Sikström \& Garcia, 2017) asks participants to rate (1 = not offensive at all, 5 = very offensive $)$ how

191 offensive they perceived 30 frequently used swear words (e.g., "fuck", "shit", "bitch”, "cunt”,

192 "damn", and "asshole"). An offensiveness score was computed by simply summarizing the 193 average value of the 30 taboo words (Cronbach's $\alpha=.95)$.

Swear Words' Frequency. The Taboo Words’ Usage Inventory (Rosenberg, Sikström \& 195 Garcia, 2017) asks participants to rate $(1=$ rarely or never, $5=$ very often $)$ how often they use each 196 one of the 30 frequently used swear words from the Taboo Words' Offensiveness Inventory (e.g., 197 “fuck", “shit”, “bitch", “cunt”, “damn”, and "asshole”). A frequency score was computed by 198 simply summarizing the average value of the 30 taboo words (Cronbach's $\alpha=.94)$.

199

200 201 202 203 204 205 206 207 208 209

\section{Statistical Procedure}

The scores in each dark trait were first transformed to percentiles and then used to divide subjects into high and low percentiles in each of the three dark traits: Machiavellianism, narcissism, and psychopathy (see Garcia, 2018). Then the participants were clustered according to all the possible combinations of high/low scores in Machiavellianism $(\mathrm{M} / \mathrm{m})$, narcissism $(\mathrm{N} / \mathrm{n})$, and psychopathy $(\mathrm{P} / \mathrm{p})$ to define the eight possible Dark Triad profiles: MNP "maleficent" $\left(n_{1}=247,24.7 \%\right), \mathrm{MNp}$ "manipulative narcissistic" $\left(n_{1}=78,7.8 \%\right), \mathrm{MnP}$ "anti-social" $\left(n_{1}=124,12.4 \%\right)$, Mnp "Machiavellian" $\left(n_{1}=52,5.2 \%\right), \mathrm{mNP}$ "psychopathic narcissistic" $\left(n_{1}=72,7.2 \%\right), \mathrm{mNp}$ "narcissistic" $\left(n_{1}=122,12.2 \%\right), \mathrm{mnP}$ "psychopathic" $\left(n_{1}=99,9.9 \%\right)$, and mnp "benevolent" $\left(n_{1}\right.$ $=206,20.6 \%$.

\section{Results and Discussion}

Paired $t$-tests were used to investigate the differences in perception and usage of swear words between individuals with malevolent character profiles who differed in one of the dark character 
212 traits but were similar in the other two. In addition, correlation analyses were also conducted in

213 order to investigate the added value of the profile analyses in relation to linear correlations between

214 the dark traits and both swear word's offensiveness and usage.

215 While the correlation analyses indicated a significant positive correlation between

216 Machiavellianism and swear word usage $(r=.31, p<.001)$ and a significant but very low negative

217 correlation between Machiavellianism and swear word offensiveness $(r=-.15, p<.001)$, the Dark

218 Cube analyses indicated a more complex relationship (see Table 1). For instance, high levels of

219 Machiavellianism were associated to high levels of swear word usage and to low offensiveness

220 when both narcissism and psychopathy were low (Mnp vs. mnp). Moreover, Machiavellianism

221 was also associated to high swear word usage when narcissism was low and psychopathy was high

222 (MnP vs. mnP) and also when both narcissism and psychopathy were high (MNP vs. mNP). In

223 other words, individuals high in Machiavellianism seem to use swear words very frequently. The

224 only exception is when narcissism is high and psychopathy is low (MNp vs. mNp). This specific

225 finding was only discerned when the dark profiles were analyzed and suggests that a sub-group of

226 individuals with a tendency for manipulativeness, a cynical worldview and lack morality (i.e., high

227 Machiavellianism) do not use swear words frequently if they at the same time have a sense of

228 grandiosity and vulnerable self-esteem (i.e., high narcissism) and are high in conscientiousness

229 and low in impulsivity (i.e., low psychopathy). In addition, another specific finding from the Dark

230 Cube analyses, was that individuals with a Machiavellian profile (Mnp), compared to individuals

231 with a benevolent profile (mnp), actually were the ones that really do not have a problem with

232 swearing, they both use it frequently (Cohen's $d=0.33$ ) and found the 30 swear words less

233 offensive (Cohen's $d=-0.27$ ). The Machiavellian profile was not common in this sample (only

$2345.2 \%$ ), but in a sample of 18,192 individuals the Machiavellian profile was almost twice as 
235 common (9.60\%; Garcia, 2018), thus, depending on the sample composition, this might influence

236 the findings when linear analyses are implemented.

237

With regard to narcissism, the correlation analyses indicated a significant positive but very

238 low correlation between narcissism and swear word usage $(r=.16, p<.001)$ and no significant

239 correlation between narcissism and swear word offensiveness $(r=-.01, p=.802)$. The Dark Cube

240 analyses (see Table 1), however, indicated that the level of offensiveness perceived in the swear

241 words was associated to high levels of narcissism only when Machiavellianism was high and

242 psychopathy was low (MNp vs. Mnp). This association was positive and moderate (Cohen's $d=$

243 0.40). That is, in contrast to the correlation analyses, these analyses indicated that individuals with

244 high levels of grandiosity and vulnerable self-esteem (i.e., high narcissism) found the 30 swear

245 words more offensive if they were highly manipulative (high Machiavellianism) and high in

246 conscientiousness and low in impulsivity (i.e., low psychopathy). Nevertheless, high narcissism

247 was associated to high levels of swear word usage when both Machiavellianism and psychopathy

248 were low (mNp vs. mnp). Hence, narcissism seem to have an effect in both high frequency usage

249 of swear words and high offensiveness of swear words depending on the interaction between the

250 other two dark traits within the person.

251 Finally, with regards to psychopathy, the correlation analyses indicated a significant

252 positive correlation between psychopathy and swear word usage $(r=.28, p<.001)$ and a

253 significant but very low negative correlation between psychopathy and swear word offensiveness

$254(r=-.19, p<.001)$. The Dark Cube analyses (see Table 1) indicated that high levels of psychopathy

255 were indeed associated to high levels of swear words' usage in most of the cases (i.e., three out of

256 four comparisons: MNP vs. MNp; MnP vs. Mnp; mnP vs. mnp). Nevertheless, these analyses also

257 indicated that when Machiavellianism was low and narcissism was high (mNP vs. mNp), then high 
258 psychopathy was not significantly associated to high usage of swear words. That is, individuals

259 who are impulsive, anti-social, and thrill-seeking (high psychopathy) do not use swear words

260 frequently if they also have low tendency towards manipulativeness (i.e., low Machiavellianism)

261 and at the same time high tendency to grandiosity (i.e., high narcissism). Last but not the least, the

262 association psychopathy-swear words' offensiveness was not a clear-cut. High levels of

263 psychopathy were associated to low offensiveness only when both narcissism and psychopathy

264 were high (MNP vs. MNp).

265

266

267

268

269

270

271

272

273

274

$275\left(N_{2}=309, M_{\text {age }}=30.97 \pm 9.63\right)$.

\section{$276 \quad$ Measures}

277 Dark Traits. As in Study 1, the Dark Triad Dirty Dozen (Jonason \& Webster, 2010) was used to 278 measure the three dark character traits: Machiavellianism (Cronbach's $\alpha=.82$ ), narcissism 279 (Cronbach's $\alpha=.77)$, and psychopathy (Cronbach's $\alpha=.77)$. 

nine-point scale ranging from 0 to 20 or more and items such as "With how many different partners have you had sexual intercourse on one and only one occasion?" (Cronbach's $\alpha=.79$ ); attitude

A global sociosexual orientation composite (i.e., the sum of all three dimensions) was also calculated (Cronbach's $\alpha=.87)$.

\section{Statistical Procedure}

291 The same procedure as in Study 1 was followed to create all the eight possible combinations of 292 high and low dark trait percentile scores or Dark Triad profiles: MNP "maleficent" $\left(n_{2}=67\right.$, 293 21.7\%), MNp "manipulative narcissistic" $\left(n_{2}=31,10.0 \%\right), \mathrm{MnP}$ "anti-social” $\left(n_{2}=34,11.0 \%\right)$,

294 Mnp "Machiavellian" $\left(n_{2}=23,7.4 \%\right), \mathrm{mNP}$ "psychopathic narcissistic" $\left(n_{2}=15,4.9 \%\right), \mathrm{mNp}$ 295 "narcissistic" $\left(n_{2}=45,14.6 \%\right), \mathrm{mnP}$ "psychopathic" $\left(n_{2}=24,7.8 \%\right)$, and mnp "benevolent" $\left(n_{2}=\right.$ $29670,22.7 \%)$.

\section{Results and Discussion}

298 Paired $t$-tests were used to investigate the differences in sociosexual orientation (behavior, attitude, 299 desire, and global sociosexual orientation) between individuals with malevolent character profiles 300 who differed in one of the dark character traits but were similar in the other two. As in Study 1, 301 correlation analyses were also conducted in order to investigate the added value of the profile 302 analyses in relation to linear correlations between the dark traits and sociosexuality. 

components of sociosexuality (Behavior: $r=.26, p<.001$; Attitude: $r=.28, p<.001$; Desire: $r=$ $.31, p<.001)$ and to the global sociosexuality composite $(r=.35, p<.001)$. However, the dark profiles comparison showed that this was consistent only when individuals with a Machiavellian profile (Mnp) were compared to individuals with a benevolent profile (mnp). That is, high levels of Machiavellianism were associated to a tendency to frequently having encounters of uncommitted sex (i.e., high sociosexual behavior), a promiscuous attitude to uncommitted sex (i.e., high sociosexual attitude), heightened sexual interest (i.e., high sociosexual desire), and high levels of global sociosexual orientation, only when both narcissism and psychopathy were low at the same time (Mnp vs. mnp). What is even more, this association was relatively more accentuated in the Dark Cube analyses where Cohen's $d$ varied between 0.45 to 0.64 . Hence, suggesting that the correlation analyses are correct for only those with a Machiavellian profile, which was $7.4 \%$ of the population in this study. Additionally, high levels of Machiavellianism were also associated to high levels of global sociosexual orientation when both narcissism and psychopathy were high 317 (MNP vs. mNP). See Table 2. to all components of sociosexuality (Behavior: $r=.17, p<.001$; Attitude: $r=.21, p<.001$; Desire: $r=.27, p<.001)$ and to the global sociosexuality composite $(r=.27, p<.001)$. However, the Dark

321 Cube analyses indicated that high levels of narcissism were associated to frequently having 322 encounters of un-committed sex (i.e., high sociosexual behavior), only when the other two dark 323 character traits were high (MNP vs. MnP). Additionally, high levels of narcissism were associated 324 to a promiscuous attitude to uncommitted sex (i.e., high sociosexual attitude), heightened sexual 325 interest (i.e., high sociosexual desire), and high levels of global sociosexual orientation when both 
326 Machiavellianism and psychopathy were low (mNp vs. mnp). In other words, an individual with a

327 narcissistic profile, approves and desires promiscuous sex encounters without emotional bonding,

328 but actually does it only when she/he is also high in both Machiavellianism and psychopathy. That

329 being said, the profile analyses showed that the linear correlations might only apply to individuals

330 with a narcissistic profile, which was $14.6 \%$ of the population in this study.

331 Finally, the correlation analyses indicated that psychopathy was positively associated to all 332 components of sociosexuality (Behavior: $r=.14, p<.001$; Attitude: $r=.22, p<.001$; Desire: $r=$ $333.23, p<.001)$ and to the global sociosexuality composite $(r=.25, p<.001)$. However, the Dark

334 Cube analyses indicated that high levels of psychopathy were associated to a promiscuous attitude

335 to uncommitted sex (i.e., high sociosexual attitude), heightened sexual interest (i.e., high 336 sociosexual desire), and high levels of global sociosexual orientation only when both 337 Machiavellianism and narcissism were low (mnP vs. mnp). In addition, both sociosexual attitude 338 and global sociosexual orientation were positively associated to psychopathy only when 339 Machiavellianism and narcissism were low (MNP vs. MNp). These complex interactions also 340 discerned that frequently having encounters of un-committed sex (i.e., high sociosexual behavior) 341 was not related to psychopathy. In other words, that type of behavior was only associated to high

342 levels of psychopathy, when the other two traits varied and psychopathy was constant.

$\underline{\text { Table } 2 \text { should be about here }}$

\section{General Discussion}

345 The aims in this set of studies were to investigate the relationship between malevolent character 346 traits and "dirty" behavior (i.e., swearing and sociosexual orientation) using non-linear methods

347 (i.e., comparisons between individuals who differed in one malevolent character trait but were 348 alike in the other). As shown by the discrepancies between the results from the correlation analyses 
349 and the results from the paired t-test, the Dark Cube approach considers the complexity of 350 processes within the person (cf. Cloninger \& Zohar, 2011). At a general level, the results of this

351 nonlinear approach suggested that the frequent usage, not level of offensiveness, of swear words

352 was associated to Machiavellianism and narcissism. In other words, individuals with high levels

353 in these traits might swear and are verbally offensive often because they do not see swearing as

354 offensive (cf. with the attitude-behavior-cognition-hypothesis of taboo words; Rosenberg,

355 Sikström \& Garcia, 2017). Moreover, a promiscuous sexual attitude and desire were related to

356 each dark trait only when the other two were low. Additionally, promiscuous sociosexual behavior

357 was not associated to these malevolent character traits. That is, individuals high in the dark traits

358 are willing to and have the desire to engage in sexual relations without closeness, commitment,

359 and other indicators of emotional bonding. However, they do not report high levels of previous

360 sexual experience, relationships, and infidelity. Hence, they approve and desire for it, but they are

361 not actually doing it.

362

Some important limitations are the fact that the present study was cross-sectional and that

363

364

365

366

367

368

369

370 Granjard, Cloninger \& Sikström, 2020). In addition, individuals' narratives have also been found

371 as predictive of personality traits (e.g., Garcia \& Sikström, 2014; Garcia, Kjell \& Sikström, 2013, 
372 2014, 2020). Thus, self-reported dark character traits are probably good measures that are

373 predictive of actual malevolent and "dirty" behavior (see also Moradi, Garcia, Quaquebeke, Filep

$374 \&$ Hunter, 2015).

375 Nevertheless, the most important limitation is actually the measure we used here to 376 operationalize the dark triad (i.e., the Dark Triad Dirty Dozen). First of all, we opted to use a 7377 point Likert scale (cf. Jonason \& Luévano, 2013), but other studies have used a 5-point Likert 378 scale (e.g., Jonason, Li, \& Czarna, 2013; Jonason, Slomski, \& Partyka, 2012) or even a 9-point 379 Likert scale (e.g., Jonason \& Webster, 2010). This variation makes it difficult to compare samples, 380 thus, our findings need to be replicated using more reliable measures of the Dark Triad (see also 381 Persson, 2019). Secondly, the validity of the Dark Triad Dirty Dozen has been criticized (e.g., Lee, 382 Ashton, Wiltshire, et al., 2013; Miller \& Lynam, 2012; Paulhus \& Jones, 2014). Some studies have 383 actually suggested that the Dark Triad Dirty Dozen actually measures a Dark Dyad: an anti-social 384 trait (an amalgamation of Machiavellianism and psychopathy) and narcissism (e.g., Garcia \& 385 Rosenberg, 2016; Kajonious, Persson, Rosenberg \& Garcia, 2016; Persson, Kajonious, Rosenberg 386 \& Garcia, 2016). In addition, besides the methodological issues with the Dark Triad Dirty Dozen, 387 conceptually, human personality and specifically character involves how we view our-selves, our 388 relationship with others and society, and our existence as a whole (Cloninger, 2004). This ternary 389 awareness of the self (i.e., the self, others and/or something greater that the self) is whole system 390 unit that is biopsychosocial in nature (Cloninger, 2004). In this context, while narcissism may 391 correspond to character in relation to the self and the antisocial amalgamated Machiavellianism392 psychopathy trait may correspond to character in relation to others, the Dark Triad seems to lack 393 a character that corresponds to spirituality or the view of the self in relation to something bigger 
394 that the self (Garcia \& Rosenberg, 2016). If it is so, the traits included in the Dark Cube as a model 395 of dark and malevolent character profiles need to be reconsidered.

396 Finally, it is plausible to argue that calling swearing and high scores in sociosexuality for 397 "dirty" behaviors is a bit too much. That being said, swearing is commonly known as "dirty" 398 language (Jay, 2000). Even the measure used here for the dark traits is known as the Dark Triad 399 "Dirty" Dozen, that is referring to a "quick and dirty" measure. Nonetheless, promiscuous sexual 400 behavior or high scores in sociosexuality are not necessary seen as "dirty" in all cultures and 401 contexts (Davis \& 1987). Related to this, some might argue that the dark traits have been 402 associated with some of humanities' greatest vices, but also greatest virtues. Thus, suggesting that whether the traits are dark or malevolent might be in the eye of the beholder or depends on the 404 situation. For instance, some researchers have even depicted a romantic picture of an agentic 405 "James Bond" character based on the association between high scores in the Dark Triad traits and 406 being extraverted, open, emotionally stable, having high self-esteem, and with a more 407 individualistic and competitive approach to others (e.g., Jonason, Li \& Teicher, 2010). However, 408 not only have these studies low replicability and sometimes even contradictory findings (see for 409 example Garcia, Rapp Ricciardi, \& Ambjörnsson, 2016), but many of these studies do not take into consideration or discuss the fact that high agency without high communion (i.e., cooperation,

411 empathy, social tolerance, and helpfulness) and spirituality (i.e., spiritual acceptance and meaning 412 beyond the self) does not lead to a virtuous life (Cloninger, 2004). Indeed, features such as hope, 413 empathy, and respect for one's self and others emerges from a self-transcendent outlook on life 414 with a sense of participation in the boundless unity of all things or inseparable connectedness with 415 nature and other people (Cloninger, 2004; Garcia, Lester, Lucchese, Cloninger \& Cloninger, 416 2019). In other words, even if a person who is high in dark traits is agentic, without compassion, 
417 she/he will always be self-serving and egocentric. Which in other words will lead to manipulation

418 and other type of behavior that here is depicted as dark or malevolent.

419 Concluding Remarks

420 The present investigation gives a nonlinear approach to the study of the Dark Triad traits and their

421 "dirty" behavior, in this case swearing and high levels of sociosexuality. The use of person-

422 centered and non-linear methods, such as the Dark Character Cube, are helpful in the advancement

423 of a coherent theory of a biopsychosocial model of dark character. Human character is, after all, a

424 complex dynamic adaptive system (Cloninger, 2004). As such, malevolent character should

425 express the characteristics of multi-finality and equifinality. Others, however, have pointed out

426 that darkness is just the absence of light, and that we probably need to investigate the lack or

427 underdevelopment of light character traits in order to understand what makes individuals to live a

428 virtuous or a vicious life (Garcia \& Rosenberg, 2016; cf. Cloninger, 2004).

429

\section{References}

430 Bergman L. R., \& Magnusson, D. (1997). A person-oriented approach in research on 431 developmental psychopathology. Development and Psychopathology, 9, 291-319. DOI:10.1017/s095457949700206x.

433 Bergman L. R., \& Wångby M. (2014). The person-oriented approach: a short theoretical and 434 practical guide. Eesti Haridusteaduste Ajakiri, 2, 29-49. DOI: 10.12697/eha.2014.21.02b.

Buss, D. M. (2019). Evolutionary Psychology. The New Science of the Mind. New York: Routledge.

Byrne, E. (2018). Swearing Is Good for You: The Amazing Science of Bad Language. New York: Norton Company. 
439 Cicchetti, D. \& Rogosch, F. A. (1996). Equifinality and multifinality in developmental $440 \quad$ psychopatology. Developmental Psychopathology, 8, 597-600.

441 Cloninger, C. R. (2004). Feeling good: The science of well-being. New York: Oxford University 442 Press.

443 Cloninger, C. R., \& Cloninger, K. M. (2019). The psychobiology of the path to a joyful life: 444 implications for future research and practice. The Journal of Positive Psychology. DOI: $10.1080 / 17439760.2019 .1685579$.

446

447

448

449

450

451

452

453

454

455

456

457

458

459

460 genetics and biology of human temperament: a review of traditional concepts in relation to new molecular findings. Translational Psychiatry, 9:290. DOI: 10.1038/s41398-019-06214.

Cloninger, C. R., Svrakic, N. M., \& Svrakic, D. M. (1997). Role of personality self-organization in development of mental order and disorder. Development and Psychopathology, 9, 881906. DOI: $10.1017 /$ S095457949700148X.

Cloninger, C. R., \& Zwir, I. (2018). What is the natural measurement unit of temperament: single traits or profiles?. Philosophical transactions of the Royal Society of London. Series B, Biological sciences, 373(1744), 20170163. DOI: 10.1098/rstb.2017.0163.

Cloninger, C. R., \& Zohar, A, H. (2011). Personality and the perception of health and happiness. Journal of Affective Disorder, 128, 24-32. DOI: 10.1016/j.jad.2010.06.012.

Costa Jr., P. T., McCrae, R. R. \& Dye, D. A. (1991). Facet scales for agreeableness and conscientiousness: a revision of the NEO personality inventory. Personality and Individual Differences, 12, 887-898. 
461 Davis, D. L., \& Whitten, R. G. (1987). The Cross-Cultural Study of Human Sexuality. Annual 462 Review of Anthropology, 16, 68-98.

463 Furnham, A., Richards, S. C., \& Paulhus, D. L. (2013). The Dark Triad of personality: A 10 year 464 review. Social and Personality Psychology Compass, 7, 199-216.

465 Garcia, D. (2018). Dark Cube. In V. Zeigler-Hill \& T. Shackelford (Eds.), Encyclopedia of 466 Personality and Individual Differences (pp. 1-6). Cham, Switzerland: Springer. DOI: 467 10.1007/978-3-319-28099-8_2302-1.

468

469

470

471

472

473

474

475

476

477

478

479

480

481

482 Profiles: Differences and Similarities in Psychopathy, Machiavellianism, and Narcissism. Sage Open, 5, 4. DOI: 10.1177/2158244015615167.

Garcia, D. \& González Moraga, F. R. (2017). The Dark Cube: Dark Profiles Character Profiles and OCEAN. PeerJ 5:e3845. DOI: 10.7717/peerj.3845.

Garcia, D., Kjell, O. N. E., \& Sikström, S. (2013). The Dark Triad, Happiness and Words Related to Happiness. 3rd World Congress on Positive Psychology. Los Angeles, California, USA.

Garcia, D., Kjell, O. N. E., \& Sikström, S. (2014). Happy but Dark: Using Quantitative Semantics to Investigate Facebook Status Updates. 26th Association for Psychological Science Annual Convention. San Francisco, California, USA.

Garcia, D., Kjell, O. N. E., \& Sikström, S. (2020). Expressions of Malevolent Character are Triggered when Posting on Facebook. 32 ${ }^{\text {nd }}$ Association for Psychological Science Annual Convention. Chicago, Illinois, USA.

Garcia, D., Lester, N., Lucchese, F., Cloninger, K. M., \& Cloninger, C. R. (2019). Personality and the Brain: Person-Centered Approaches. In D. Garcia, T. Archer, \& R. M. Kostrzewa 
(Eds.), Personality and Brain Disorders: Associations and Interventions. Cham, Switzerland: Springer.

485 Garcia, D., Rapp Ricciardi, M., \& Ambjörnsson, A. (2016). Dark and Agentic as James Bond? 486 Understanding Group and Leader (UGL) Coaches' Personality Profile. $28^{\text {th }}$ Association for 487 Psychological Science Annual Convention. Chicago, Illinois, USA.

488

489

490

491

492

493

494

495

496

497

498

499

500

501

502

503

504

505 4:e1675. DOI: 10.7717/peerj.1675.

Garcia, D., Rosenberg, P., González Moraga, F. R., \& Rapp Ricciardi, M. (2018). Dark Time Matter: Dark Character Profiles and Time Perspective. Psychology, 9, 63-79. DOI: 10.4236/psych.2018.91005.

Garcia, D., Rosenberg, P., Nima, A. A., Granjard, A., Cloninger, K. M., \& Sikström, S. (2020). Validation of two Short Personality Inventories using Self-descriptions in Natural Language and Quantitative Semantics Test Theory. Frontiers in Psychology, 11:16. DOI: 10.3389/fpsyg.2020.00016.

Garcia, D., \& Sikström, S. (2014). The Dark Side of Facebook - Dark Triad of Personality Predicts Semantic Representation of Status Updates. Personality and Individual Differ-ences, 67, 92-94 DOI: 10.1016/j.paid.2013.10.001.

González Moraga, F. R. (2015). La tríada oscura de la personalidad: maquiavelismo, narcisismo y psicopatía. Una mirada evolutive [The dark triad of personality: Machiavellianism, narcisssim and psychopathy. An evolutionary perspective]. Revista Criminalidad, 57 (2): $253-265$.

González Moraga, F. R., Nima, A. A., \& Garcia, D. (2017). Sex and Dark Times’ Strategy: Dark Triad and Time Perspective. PsyCh Journal, 6, 98-99. DOI: 10.1002/pchj.153. 
506 Haddad, B., Ångman, M., Archer, T., \& Garcia D. (2016). Dark Triad, Sociosexual Orientation 507 and Religious Affiliation: An Association and Moderation Study. Clinical and 508 Experimental Psychology, 2, 124. DOI: 10.4172/2471-2701.1000124.

509 Hare R.D. (1985). Comparison of procedures for the assessment of psychopathy. Journal of 510 Consulting and Clinical Psychology, 53, 7-16. DOI: 10.1037/0022-006X.53.1.7.

511 Jay, T. (2000). Why we curse: A neuro-psycho-social theory of speech. Philadelphia, PA: John 512 Benjamins.

513 Jay, T., Janschewitz, K. (2008). The pragmatics of swearing. Journal of Politeness Research, 4, 514 $267-288$.

515

John, O. P., \& Srivastava, S. (1999). The Big Five trait taxonomy: History, measurement, and 516

517 theoretical perspectives. In Pervin, L. A., \& John, O. P. (Eds). Handbook of personality: Theory and research (102-138). Elsevier.

518 Jonason, P. K., \& Buss, D. M. (2012). Avoiding entangling commitments: Tactics for 519

520 implementing a short-term mating strategy. Personality and Individual Differences, 52, 606-610. DOI: 10.1016/j.paid.2011.12.015.

521 Jonason, P. K., Li, N. P., \& Czarna, A. Z. (2013). Quick and Dirty: Some psychosocial costs

522 associated with the Dark Triad in three countries. Evolutionary Psychology, 11, 172-185.

523 Jonason, P. K., Li, N. P., \& Teicher, E. A. (2010). Who is James Bond?: The Dark Triad as an 524 Agentic Social Style. Individual Differences Research, 8, 111-120.

525 Jonason, P. K., Li, N. P., Webster, G. W., Schmitt, D. P. (2009). The Dark Triad: Facilitating short526 term mating in men. European Journal of Personality, 23, 5-18.

527 Jonason, P. K., \& Luévano, V. X. (2013). Walking the thin line between efficiency and accuracy: 528

529 Validity and structural properties of the Dirty Dozen. Personality and Individual Differences, 55, 76-81. 
530 Jonason, P. K., Slomski, S., \& Partyka, J. (2012). The Dark Triad at work: How toxic employees 531 get their way. Personality and Individual Differences, 52, 449-453.

532 Jonason P. K., \& Webster, G. D. (2010). The Dirty Dozen: A Concise Measure of the Dark Triad. 533 Psychological Assessment, 22, 420-432.

534 Jones, D. N. \& Paulhus, D. L. (2009). Machiavellianism. In M. R. Leary \& R. H. Hoyle (Eds.). 535 Handbook of Individual Differences in Social Behavior (pp. 93-108). New York: Guilford. 536 Jones, D. N., \& Paulhus, D. L. (2014). Introducing the short Dark Triad (SD3): A brief measure 537 of dark personality traits. Assessment, 21, 28-41. DOI: 10.1177/1073191113514105.

538 Kajonius, P. J., Persson, B. N., Rosenberg, P., \& Garcia, D. (2016). The (mis)measurement of the 539 Dark Triad Dirty Dozen: Exploitation at the Core of the Scale. PeerJ, 4:e1748. DOI: $540 \quad 10.7717$ peerj. 1748.

541 Lee, K., Ashton, M. C., Wiltshire, J., Bourdage, J. S., Visser, B. A., \& Gallucci, A. (2013). Sex, 542 543 power, and money: Prediction from the Dark Triad and Honesty-Humility. European Journal of Personality, 27, 169-184.

544 Miller, J. D., \& Lynam, D. R. (2012). An examination of the Psychopathic Personality Invento545 ry's nomological network: A meta-analytic review. Personality Disorders: Theory, Re546 search, and Treatment, 3, 305-326.

547 Moradi, S., Garcia, D., Quaquebeke, N., Filep, S., \& Hunter, J. (2015). Dark Triad among 548 Flourishing People: Moral Centrality as an Indicator. 8th Self Biennial International 549 Conference. Kiel, Germany.

550 Paulhus, D. L., \& Jones, D. N. (2014). Measuring dark personalities. In G. J. Boyle, D. H. 551 Saklofske \& G. Matthews (Eds.), Measures of personality and social psychological constructs. San Diego, CA: Academic Press. 
553 Paulhus D. L., \& Williams, K. M. (2002). The Dark Triad of personality: Narcissism, 554 Machiavellianism, and psychopathy. Journal of Research in Personality, 36, 556-563.

555 Persson, B. N. (2019). The Latent Structure of the Dark Triad: Unifying Machiavellianism and 556 Psychopathy. Doctoral thesis, University of Turku, Finland, UA.

557 Persson, B. N., Kajonius, P. J., Rosenberg, P., \& Garcia, D. (2016). The Single Item Dirty Dark 558 Triad (SIDDT): Exploitation of Others. 28th Association for Psychological Science Annual 559 Convention. Chicago, Illinois, USA.

560 Penke L., \& Asendorf, J. B. (2008). Beyond Global Sociosexual Orientations: A More Differen561 tiated Look at Sociosexuality and its Effects on Courtship and Romantic Relationships. $562 \quad$ Journal of Personality and Social Psychology, 95, 1113-1135.

563 Rosenberg, P., Sikström, S., \& Garcia, D. (2017). The A(ffective) B(ehavioral) C(ognitive) of 564 565 Taboo Words in Natural Language: The Relationship Between Taboo Words’ Intensity and

566 Frequency. Journal of Language and Social Psychology, 36, 306-320. DOI: 10.1177/0261927X16660830.

567 568

Stephens, R., Atkins, J., \& Kingston, A. (2009). Swearing as a Response to Pain. NeuroReport, 20, 1056-1060. DOI: 10.1097/WNR.0b013e32832e64b1.

569 570

Sumner, C., Byers, A., Boochever, R., \& Park, G.J. (2012). Predicting Dark Triad Personality Traits from Twitter Usage and a Linguistic Analysis of Tweets. 2012 11th International 571 Conference on Machine Learning and Applications, 2, 386-393.

572 Vernon, P. A., Villani, V. C., Vickers, L. C., \& Harris, J. A. (2008). A behavioral genetic 573 investigation of the Dark Triad and the Big 5. Personality and Individual Differences, 44, 574 445-452. 
575 Vrangalova, Z., \& Ong, A. D. (2014). Who Benefits from Casual Sex? The Moderating Role of 576 Sociosexuality. Social Psychological and Personality Science, 5, 883-891. DOI:

577 $10.1177 / 1948550614537308$.

578 Zwir, I., Del-Val, C., Arnedo, J., Pulkki-Råback, L., Konte, B., Yang, S. S, Romero-Zaliz, R., 579 Hintsanen, M., Cloninger, K. M., Garcia, D., Svrakic, D. M., Lester, N., Rozsa, S., Mesa, 580 A., Lyytikäinen, L-P., Giegling, I., Kähönen, M., Martinez, M., Seppälä, I., Raitoharju, E., 581 de Erausquin, G., Mamah, D., Raitakari, O., Rujescu, D., Postolache, T. T., Gu, C. C.,

582

583

584

585

586

587

588

589

590

591

592 593

594

595

596
Sung, J., Lehtimäki, T., Keltikangas-Järvinen, L., \& Cloninger, C. R. (2018a). Three Genetic-Environmental Networks for Human Personality. Molecular Psychiatry. DOI: 10.1038/s41380-019-0579-x.

Zwir, I., Arnedo, J., Del-Val, C., Pulkki-Råback, L., Konte, B., Yang, S. S, Romero-Zaliz, R., Hintsanen, M., Cloninger, K. M., Garcia, D., Svrakic, D. M., Rozsa, S., Martinez, M., Lyytikäinen, L-P., Giegling, I., Kähönen, M., Hernandez-Cuervo, H., Seppälä, I., Raitoharju, E., de Erausquin, G. A., Raitakari, O., Rujescu, D., Postolache, T. T., Sung, J., Keltikangas-Järvinen, L., Lehtimäki, T., \& Cloninger, C. R. (2018b). Uncovering the Complex Genetics of Human Temperament. Molecular Psychiatry. DOI: 10.1038/s41380018-0264-5.

Zwir, I., Arnedo, J., Del-Val, C., Pulkki-Råback, L., Konte, B., Yang, S. S, Romero-Zaliz, R., Hintsanen, M., Cloninger, K. M., Garcia, D., Svrakic, D. M., Rozsa, S., Martinez, M., Lyytikäinen, L-P., Giegling, I., Kähönen, M., Hernandez-Cuervo, H., Seppälä, I., Raitoharju, E., de Erausquin, G. A., Raitakari, O., Rujescu, D., Postolache, T. T., Sung, J., Keltikangas-Järvinen, L., Lehtimäki, T., \& Cloninger, C. R. (2019a). Uncovering the 

0263-6.

599 Zwir, I., Mishra, P., Del-Val, C., Gu, C. C., de Erausquin, G., Lehtimäki, T., \& Cloninger, C. R. 600 (2019b). Uncovering the complex genetics of human personality: Response from authors 601 on the PGMRA model. Molecular Psychiatry. doi: 10.1038/s41380-019-0399-z. 


\section{Table $\mathbf{1}$ (on next page)}

Results from the t-tests for each Dark Triad character trait for swear words' frequency and offensiveness 
1 Table 1. Results from the t-tests for each Dark Triad character trait for swear words' frequency and offensiveness. The black cells

2 indicate significant results.

\begin{tabular}{|c|c|c|c|c|c|c|c|}
\hline \multirow[t]{2}{*}{ Dark Trait } & \multirow[t]{2}{*}{ Dark Profile } & \multicolumn{3}{|c|}{ Swear Words' Frequency } & \multicolumn{3}{|c|}{$\underline{\text { Swear Words' Offensiveness }}$} \\
\hline & & $t$ & $p$ & Cohen's $d$ & $t$ & $p$ & Cohen's $d$ \\
\hline \multirow{4}{*}{ Machiavellianism } & MNP vs. mNP & 2.89 & .004 & 0.32 & -0.60 & .55 & -0.07 \\
\hline & MNp vs. mNp & 0.61 & .54 & 0.09 & 0.54 & .59 & 0.08 \\
\hline & $\mathrm{MnP}$ vs. mnP & 2.96 & .003 & 0.40 & -0.75 & .46 & -0.10 \\
\hline & Mnp vs. mnp & 2.64 & .009 & 0.33 & -2.15 & .03 & -0.27 \\
\hline \multirow{4}{*}{ Narcissim } & MNP vs. MnP & 0.40 & .69 & 0.04 & -0.23 & .82 & -0.02 \\
\hline & MNp vs. Mnp & -0.40 & .69 & -0.07 & 2.26 & .03 & 0.40 \\
\hline & mNP vs. mnP & 0.51 & .61 & 0.08 & -0.36 & .72 & -0.06 \\
\hline & $\mathrm{mNp}$ vs. mnp & 2.13 & .03 & 0.24 & -0.31 & .76 & -0.03 \\
\hline \multirow{4}{*}{ Psychopathy } & MNP vs. MNp & 3.79 & .000 & 0.42 & -3.41 & .001 & -0.38 \\
\hline & MnP vs. Mnp & 2.30 & .02 & 0.35 & -0.06 & .95 & -0.01 \\
\hline & mNP vs. mNp & 1.37 & .17 & 0.20 & -1.85 & .07 & -0.27 \\
\hline & $\mathrm{mnP}$ vs. mnp & 3.07 & .002 & 0.35 & -1.87 & .06 & -0.21 \\
\hline
\end{tabular}

3 Note: $\mathrm{M} / \mathrm{m}$ = high/low Machiavellianism; $\mathrm{N} / \mathrm{n}$ = high/low narcissism; P/p = high/low; MNP “maleficent”, MNp "manipulative

4 narcissistic”, MnP “anti-social”, Mnp "Machiavellian”, mNP “psychopathic narcissistic”, mNp "narcissistic”, mnP “psychopathic”,

5 and mnp "benevolent".

6 


\section{Table 2 (on next page)}

Results from the $t$-tests for each Dark Triad character trait for sociosexuality. 
1 Table 2. Results from the t-tests for each Dark Triad character trait for sociosexuality. The black numbers indicate significant results.

\begin{tabular}{|c|c|c|c|c|c|c|c|c|c|c|c|c|c|}
\hline \multirow[t]{2}{*}{ Dark Trait } & \multirow[t]{2}{*}{ Dark Profile } & \multicolumn{3}{|c|}{$\underline{\text { Behavior }}$} & \multicolumn{3}{|c|}{$\underline{\text { Attitude }}$} & \multicolumn{3}{|c|}{$\underline{\text { Desire }}$} & \multicolumn{3}{|c|}{$\frac{\text { Global Sociosexual }}{\underline{\text { Orientation }}}$} \\
\hline & & $t$ & $p$ & Cohen's $d$ & $t$ & $p$ & Cohen's $d$ & $t$ & $p$ & Cohen's $d$ & $t$ & $p$ & Cohen's $d$ \\
\hline \multirow{4}{*}{ Machiavellianism } & MNP vs. mNP & 1.93 & .06 & 0.43 & 1.74 & .08 & 0.39 & 1.32 & .19 & 0.29 & 2.17 & $<.05$ & 0.48 \\
\hline & MNp vs. mNp & 0.84 & .41 & 0.19 & 0.57 & .57 & 0.13 & 0.14 & .89 & 0.03 & 0.64 & .52 & 0.15 \\
\hline & MnP vs. mnP & 0.87 & .39 & 0.23 & 0.88 & .38 & 0.24 & 1.50 & .14 & 0.40 & 1.39 & .17 & 0.37 \\
\hline & Mnp vs. mnp & 3.03 & $<.01$ & 0.64 & 2.15 & $<.05$ & 0.45 & 2.23 & $<.05$ & 0.47 & 3.04 & $<.01$ & 0.64 \\
\hline \multirow{4}{*}{ Narcissism } & MNP vs. MnP & 2.31 & $<.05$ & 0.46 & 1.36 & .18 & 0.27 & 0.71 & .48 & 0.14 & 1.86 & .07 & 0.37 \\
\hline & MNp vs. Mnp & -1.02 & .31 & -0.28 & -0.05 & .96 & -0.01 & 0.59 & .56 & 0.16 & -0.16 & .56 & -0.04 \\
\hline & mNP vs. mnP & 0.29 & .77 & 0.10 & 0.08 & .94 & 0.03 & 0.61 & .55 & 0.20 & 0.26 & .70 & 0.13 \\
\hline & mNp vs. mnp & 0.83 & .41 & 0.16 & 2.00 & $<.05$ & 0.38 & 3.51 & $\begin{array}{c}< \\
.001\end{array}$ & 0.66 & 2.75 & $<.01$ & 0.52 \\
\hline \multirow{4}{*}{ Psychopathy } & MNP vs. MNp & 1.88 & .06 & 0.38 & 2.35 & $<.05$ & 0.48 & 1.72 & .09 & 0.35 & 2.63 & $<.05$ & 0.54 \\
\hline & MnP vs. Mnp & -1.42 & .16 & -0.38 & 0.76 & .45 & 0.20 & 1.30 & .20 & 0.35 & 0.48 & .63 & 0.13 \\
\hline & $\mathrm{mNP}$ vs. $\mathrm{mNp}$ & 0.16 & .87 & 0.04 & 0.45 & .64 & 0.12 & 0.09 & .93 & 0.02 & 0.31 & .76 & 0.08 \\
\hline & mnP vs. mnp & 0.49 & .62 & 0.10 & 2.07 & $<.05$ & 0.43 & 2.07 & $<.05$ & 0.44 & 2.11 & $<.05$ & 0.44 \\
\hline
\end{tabular}

2 Note: $\mathrm{M} / \mathrm{m}$ = high/low Machiavellianism; N/n = high/low narcissism; P/p = high/low; MNP "maleficent", MNp "manipulative narcissistic", MnP "anti-social",

3 Mnp "Machiavellian", mNP "psychopathic narcissistic", mNp "narcissistic", mnP "psychopathic", and mnp "benevolent”. 


\section{Figure 1}

\section{The Dark Cube}

The Dark Cube as an analogy to Cloninger's character cube, showing all eight possible combinations of high/low scores in Machiavellianism, narcissism, and psychopathy.

Note: adapted with permission from C. R. Cloninger. The directions of the arrows represent higher values. $\mathrm{M} / \mathrm{m}=$ high/low Machiavellianism; $\mathrm{N} / \mathrm{n}=$ high/low narcissism; $\mathrm{P} / \mathrm{p}=$ high/low psychopathy. Originally published in: Garcia D, Rosenberg P. (2016) The dark cube: dark and light character profiles. Peerj 4:e1675.
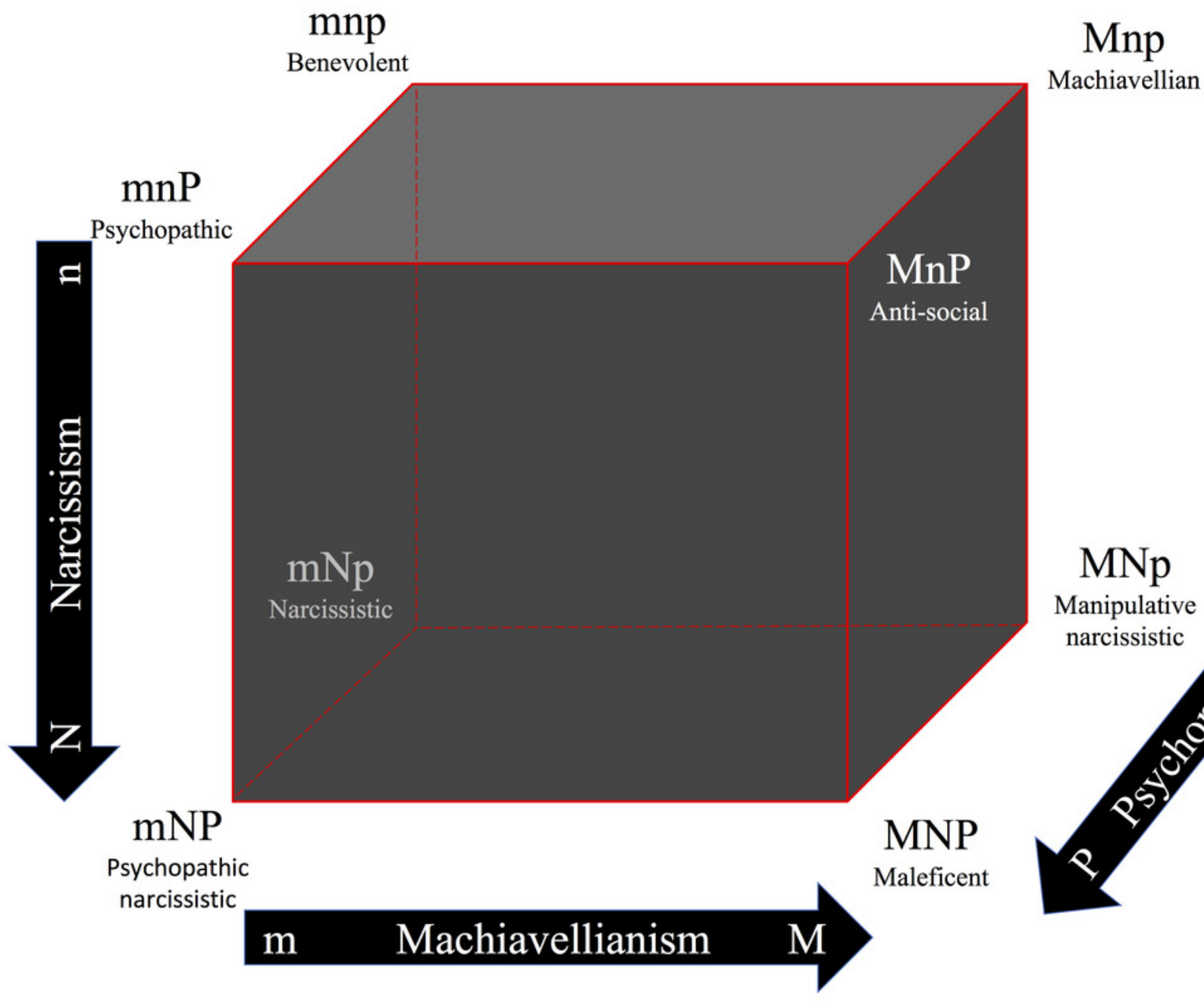

Manipulative narcissistic

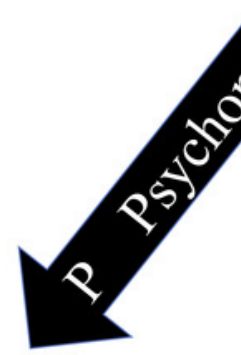

